\title{
IMPACT OF DIABETIC NEUROPATHY ON QUALITY OF LIFE AND POSTURAL BALANCE IN BRAZILIAN OLDER ADULTS
}

\section{O IMPACTO DA NEUROPATIA DIABÉTICA NA QUALIDADE DE VIDA E EQUILÍBRIO POSTURAL EM IDOSOS BRASILEIROS}

\author{
Rita de Cássia ERnandes ${ }^{1}$ (1), Guilherme Carlos Brech ${ }^{1,2}$ (1), Natália Mariana Silva Luna ${ }^{1,2}$ (i), Armando Bega ${ }^{3}$ (1),

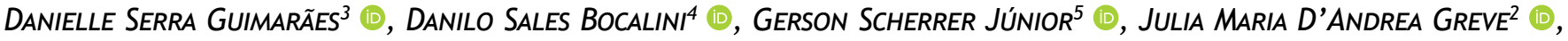 \\ LUIZ EUGÊNIO GARCEZ LEME ${ }^{2}$ (1), ANGÉLICA CASTILHO ALONSO ${ }^{1,2}$ (1)
}

1. Universidade São Judas Tadeu, São Paulo, SP, Brazil.

2. Universidade de São Paulo, Hospital das Clínicas, Medical School, Institute of Orthopedics and Traumatology, São Paulo, SP, Brazil.

3. Universidade Anhembi Morumbi, São Paulo, SP, Brazil.

4. Universidade Federal do Espírito Santo, Physiology and Experimental Biochemistry Laboratory of Physical Education Sport Center, Vitória, ES, Brazil.

5. Universidade Federal de São Paulo, São Paulo, SP, Brazil.

\section{ABSTRACT}

Objective: To analyze the impact of the Peripheral Diabetic Neuropathy (PDN) on the postural and functional balance and quality of life of Brazilian older adults. Methods: A cross-sectional study. Sixty older men and women (60-79 years) were divided into three groups: control, DM without and with PDN. The following parameters were evaluated: anthropometry; quality of life; postural balance (BESTest); functional balance in force plate (NeuroCom Balance). Results: PDN group presented significant differences compared with the other groups, with the worst performance in quality of life than DM2 without PDN in: sensory functioning $(p=0.030)$; past and future $(p=0.036)$; death and dying $(p=0.035)$. Postural balance deficit in the total score $(p=0.025)$ and biomedical constraints section $(p=0.043)$ of the BESTest, compared with DM2 without PDN $(p=0.007)$. In the functional balance (Neurocom), PDN group presented a worse performance in the time spent on the left side $(p=0.030)$ than the control group. During step up over test, the control group performed the task faster than the group with PDN $(p=0.004)$. Conclusion: This study showed that neuropaths presented worse physical performance and postural balance deficits, sensorial limitations, affecting the daily tasks and, as a consequence, decreasing the quality of life in Brazilian older adults. Level of Evidence II, Cross-sectional observational study.

Keywords: Diabetes Mellitus. Neuropathy. Postural Balance. Quality of life.

\section{RESUMO}

Objetivo: Analisar a influência da neuropatia diabética periférica (NDP) no equilíbrio postural, atividades funcionais e na qualidade de vida em idosos. Métodos: Estudo transversal. Avaliamos 60 homens e mulheres idosos (60-79 anos) divididos em três grupos: controle, DM sem e com NDP. Foram avaliados: antropometria; qualidade de vida; equilibrio postural (BESTest); atividades funcionais pelo equilíbrio funcional na placa de força (NeuroCom Balance). Resultados: Grupo NDP apresentou diferenças comparado a outros grupos, pior desempenho na qualidade de vida que o DM2 sem NDP em: funcionamento sensorial ( $p=0,030)$; passado e futuro $(p=0,036)$; morte e morrer $(p=0,035)$. Déficit de equilíbrio postural no escore total $(p=0,025)$ e seção de restrições biomédicas $(p=0,043) d o$ BESTest comparado ao DM2 sem NDP $(p=0,007)$. No equilíbrio funcional (Neurocom), o grupo NDP apresentou pior desempenho no tempo gasto no lado esquerdo $(p=0,030)$ comparado ao grupo controle. Durante a etapa de teste, o grupo controle executou a tarefa mais rapidamente que o grupo NDP $(p=0,004)$. Conclusão: Neuropatas apresentaram pior desempenho físico e déficits no equilíbrio postural, limitações sensoriais, afetando as tarefas diárias da doença e, consequentemente, diminuição da qualidade de vida em idosos brasileiros. Nível de Evidência II, Estudo observacional transversal.

Palavras-chave: Diabetes Mellitus. Neuropatia. Equilíbrio Postural. Qualidade de vida.

Citation: Ernandes RC, Brech GC, Luna NMS, Bega A, Guimarães DS, Bocalini DS, Scherrer G Jr., Greve JM, Leme LEG, Alonso AC. The impact of diabetic neuropathy on quality of life and postural balance in Brazilian older adults. Acta Ortop Bras. [online]. 2020;28(6):275-279. Available from URL: http://www.scielo.br/aob.

\section{INTRODUCTION}

It is estimated that 425 million people have Diabetes Mellitus (DM) in the world, and by 2045, there will be about 629 million people. Today, 98 million older adults (65-79 years) are susceptible to the disease, and by 2045, there could be 191 million. ${ }^{1}$
Peripheral Diabetic Neuropathy (PDN) is one of the most frequent complications of $\mathrm{DM},{ }^{2}$ which is progressive and irreversible. This complication is related to the reduction in sensory and motor peripheral pathways, possibly due to abnormal neuromuscular response to postural disorders. Thus, it leads to an inability to detect temperature,

All authors declare no potential conflict of interest related to this article.

The study was conducted at Universidade São Judas Tadeu and developed in partnership with the Kinesiology Laboratory of the Institute of Orthopedics and Traumatology at the Clinic Hospital of the Medical School, Universidade de São Paulo (HCFMUSP) and Universidade Anhembi Morumbi.

Correspondence: Guilherme Carlos Brech. Laboratório de Estudos do Movimento. Rua Dr. Ovídio Pires de Campos, 333, 2ªndar, São Paulo, SP, Brazil, 04503010. guibrech@gmail.com 
vibration, pressure and proprioception changes, modifying thus the static and dynamic postural balance. ${ }^{2-4}$

In addition, complications related to DM can reduce autonomy, individual and social well-being, thus reducing patients' quality of life (QoL). 5,6

However, it is necessary to understand and verify if the loss of postural balance gets worse with patients with PDN, consequently worsening the quality of life. Additionally, the loss of postural balance can increase the risk of fall and worsen the quality of life. This way, specific interventions could be adapted to reduce falls and physical incapacities in older adults with DM2.

The aim of the study was to analyze the influence of PDN on the postural and functional balance and quality of life of Brazilian older adults.

\section{MATERIALS AND METHODS}

\section{Study location and ethical issues}

This study was developed at the Motion Study Laboratory of the Institute of Orthopedics and Traumatology, at the Falls Prevention Program in the Department of Geriatrics, Hospital das Clinicas $(\mathrm{HC})$, Medical School, Universidade de São Paulo (FMUSP) with the approved granted by Ethical Committee (registration number: 60952116.4.0000.0089) and developed in partnership with the Universidade Anhembi Morumbi. All participants provided written informed consent.

\section{Type of study and subjects}

This was a cross-sectional study that used as convenience sampling the older adults of a community. Sixty older adults both female and male between 60 and 79 years old were divided into three groups: 1) Control; 2) DM2 without PDN and 3) DM2 with PDN.

The subjects were recruited from the Integrated Health Center (CIS), endocrinology department of the Universidade Anhembi Morumbi. The inclusion criteria for both groups were: absence of foot ulcers and/or partial and total lower limb amputations, disease or functional impairment of any system: auditory, vestibular, proprioceptive, neurological, musculoskeletal; no use medications that could affect the postural balance; irregular activity according to the IPAQ questionnaire; and presence of normative parameters in the cognitive test (MoCA).

For DM2 groups, the disease should have been present for more than three years, subdivided into two groups: without PDN, with tactile sensitivity and preserved blood pressure; and with PDN with loss of tactile and sensitivity pressure. As exclusion criteria: if for any reason, subjects could not perform any of the proposed tests.

\section{Measurements}

The same researcher performed all evaluations.

\section{PDN measurements and subjective questionnaires}

Personal data, such as medical history, number of falls (Participants were questioned about a fall event, "Have you fallen?", considering fall an unintentional event that changed individuals' body position to a lower level, when compared with their initial position, whether having associated consequences or not); body mass and height were initially collected.

For confirmation of PDN the criteria used were the American Diabetes Association (ADA) criteria based on insensitivity to $10 \mathrm{~g}$ Semmes-Weinstein monofilament, for testing the thermal stimuli, two tubes were used, one preheated and one pre-cooled. The vibration perception threshold (VPT) scores were recorded to quantify the level of neuropathy with a cut off of $25 \mathrm{mV}$ as an indicator of neuropathy at recommended plantar foot sites (assessed at the great toe, fifth metatarsal, and heel of both feet using VPT Meter).
Older adults should have plantar insensitivity in four of the ten points analyzed or not distinguish temperature or vibration (decreased), to be considered PDN. ${ }^{7}$

\section{Quality of life evaluation}

All the older adults answered the World Health Organization Quality of Life Instrument-Older Adults Module (WHOQOL-OLD) questionnaire, in the Portuguese version. WHOQOL-OLD comprises 24 items divided into six domains: sensory abilities, autonomy, past-present-future activities, social participation, death and dying, and intimacy. ${ }^{8}$

\section{Balance Evaluation Systems Test (BESTest)}

Balance Evaluation Systems Test (BESTest) was used to evaluate postural balance. Containing 27 items, with a total of 36 tasks organized in six sections (biomechanical constraints, stability limits, postural responses, anticipatory postural adjustments, sensory orientation, and dynamic balance during gait, and cognitive). All domains followed the protocol established by the translation and adaptation to the Portuguese language. ${ }^{9}$

\section{Functional balance evaluation}

The postural balance assessment (posturography) was performed on the NeuroCom Balance Master ${ }^{\circledR}$ force platform system (NeuroCom International, Inc., Clackamas, OR, USA). The system uses a fixed 18 in. $\AA \sim 60$ in. dual force plate to measure the vertical forces exerted by the patient's feet ND. ${ }^{10}$ The following tests were performed:

Sit-to-stand: the sit-to-stand transfer test was done on the platform, with the individual initially sitting on a bench (height of $30 \mathrm{~cm}$ ) without a backrest, with the knees flexed at $90^{\circ}$ and the feet separated by $10 \mathrm{~cm}$ in relation to the heels. The arms were kept at the side of the body throughout the test. The subjects were instructed to stand up safely and quickly. Three repetitions of the movement were made at intervals of $30 \mathrm{sec}$ between each attempt. The parameters measured were the mean weight transfer and center of gravity (COG) sway velocity while rising. The weight transfer was the time in seconds required to voluntarily shift the COG forward, beginning in the seated position and ending with full weight-bearing on the feet. The COG sway velocity documented the degree of control over the COG above the support base during the rising phase and for 5 sec thereafter. Sway was expressed in degrees per second.11 Step/Quick Turn: the older adult was advised to walk on the platform, rotate 180 degrees, and return to the starting place. The test started first to the left side and then to the right side, repeating each side three times in a 30-second interval. The measured parameters were the time required in seconds of the rotation on both sides; speed of travel in seconds in both directions. ${ }^{12}$

Step up-and-over: for this test, the subjects were instructed to step up on a $20-\mathrm{cm}$ high step, putting only one foot on the step. The other foot was expected to go directly over the step and down off the platform without contacting the step. When both feet reached the platform, after going up the step, the subjects were instructed to remain as stationary as possible. Three attempts were made for each leg, starting with the left leg. The variables evaluated in this protocol were the mean weight transfer index, mean movement time, and mean impact index. In all of the balance tests performed in this study, the subjects could only make three attempts to perform each movement in each test. If they were unable to successfully perform the test after three incomplete attempts, the test was excluded. ${ }^{10,12}$

\section{Statistical Analysi}

Data were stored in the IBM SPSS Statistics 24 program and presented by means and standard deviation. The Shapiro Wilk test was performed to verify if the variables adjusted to normality and to use the relevant comparative tests. The Chi-square test was used to compare categorical variables (gender and falls). The ANOVA test 
was used to compare the three groups with Bonferroni post hoc. The Student's t-test was used for the period of the disease in the DM2 groups, with and without NDP. The $5 \%$ level of significance was adopted throughout the analysis.

\section{RESULTS}

The gender distribution in relation to the groups was: control, 8 (40\%) women and $12(60 \%)$ men; in the group without PDN, 7 (35\%) women and 13 (65\%) men; PDN group, 11 (55\%) women and $9(45 \%)$ men $\left[\chi^{2}(p)=1.765(0.41)\right]$. Falls were more frequent in PDN groups, but with significant difference $\left[\left(\chi^{2}(p)=1,304(0,52)\right]\right.$; in the group distribution: 5 (25\%) of the control group, $3(15 \%)$ in the group without PDN and 6 (30\%) in the PDN group.

Age, a period of the disease, body mass, height, body mass index (BMI) classification, years of schooling and cognition (MoCA) did not present significant differences between the groups. Regarding the period of disease (DM2), there was a significant difference between the groups with DM2, since subjects of the group with PDN presented higher duration of disease (Table 1).

Table 1. Anthropometric characteristics; age; time disease, years of school and cognition (Moca).

\begin{tabular}{c|c|c|c}
\hline & Control & $\begin{array}{c}\text { DM2 } \\
\text { Without PDN }\end{array}$ & $\begin{array}{c}\text { DM2 } \\
\text { With PDN }\end{array}$ \\
\hline & $\begin{array}{c}\text { Mean (SD) } \\
\mathbf{n = 2 0}\end{array}$ & $\begin{array}{c}\text { Mean (SD) } \\
\mathbf{n = 2 0}\end{array}$ & $\begin{array}{c}\text { Mean (SD) } \\
\mathbf{n = 2 0}\end{array}$ \\
\hline Age (years) & $70.50(6.20)$ & $69.55(5.87)$ & $72.9(3.90)$ \\
\hline Duration of disease (years) & - & $10.35(6.22)$ & $13.30(11.30)^{\star}$ \\
\hline Body mass (Kg) & $70.50(13.70)$ & $71.55(12.62)$ & $75.0(13.7)$ \\
\hline Height (m) & $1.62(0.08)$ & $1.58(0.09)$ & $1.64(0.09)$ \\
\hline BMI (kg/m $\mathbf{2})$ & $26.54(4.17)$ & $28.18(2.87)$ & $28.26(4.10)$ \\
\hline Years of Schooling & $12.20(3.45)$ & $11.45(5.88)$ & $10.85(4.60)$ \\
\hline Cognition (MoCA) & $23.55(3.63)$ & $23.95(2.92)$ & $22.55(2.89)$ \\
\hline
\end{tabular}

ANOVA - Post Hoc Bonferroni test; $\S$ Student's t-test. * $p \leq 0.05$

SD: standard deviation; BMI: body mass index; MoCA: Montreal Cognitive Assessment.

Quality of life, assessed with the WHOQOL-OLD test, in three groups (control, diabetics without and with PDN) in the total score had a QoL classified as regular (3 to 3.9), according to the classification suggested by Fleck et al. ${ }^{13,14}$ and Power et al..$^{15}$ Among the DM2 groups, subjects without PDN were better in the following domains: sensory abilities ( $p=0.030)$, past-present-future activities $(p=0.036)$, and death and dying $(p=0.035)$. They were also better in past-present-future activities $(p=0.036)$ than the control group. There were no significant differences in relation to the other domains (autonomy, social participation, and intimacy) in the three groups (Table 2).

Table 2. Comparison of Quality of Life in groups DM2 with and without PDN and control.

\begin{tabular}{c|c|c|c}
\hline & Control & $\begin{array}{c}\text { DM2 } \\
\text { Without PDN }\end{array}$ & $\begin{array}{c}\text { DM2 } \\
\text { With PDN }\end{array}$ \\
\hline & Mean (SD) $\mathbf{n = 2 0}$ & Mean (SD) $\mathbf{n = 2 0}$ & Mean (SD) $\mathbf{n = 2 0}$ \\
\hline Intimacy & $3.5(0.8)$ & $4.0(0.7)$ & $3.6(0.7)$ \\
\hline Sensory abilities & $3.7(0.5)$ & $4.1(0.5)^{\mathrm{a}}$ & $3.5(0.9)^{\mathrm{a}}$ \\
\hline Autonomy & $3.8(0.6)$ & $3.5(0.9)$ & $3.7(0.6)$ \\
\hline PPF Activities & $3.5(0.4)^{\mathrm{b}}$ & $4.1(0.7)^{\mathrm{a}, \mathrm{b}}$ & $3.6(0.4)^{\mathrm{a}}$ \\
\hline $\begin{array}{c}\text { Social } \\
\text { Participation }\end{array}$ & $3.6(0.6)$ & $4.0(0.6)$ & $3.6(0.6)$ \\
\hline Death and Dying & $3.5(0.7)$ & $3.9(0.7)^{\mathrm{a}}$ & $3.2(1.0)^{\mathrm{a}}$ \\
\hline QoL (total) & $3.6(0.6)$ & $3.9(0.4)$ & $3.5(0.4)$ \\
\hline
\end{tabular}

ANOVA - Post hoc Bonferroni test. * $p \leq 0.05$

QoL: Quality of Life; PPF: past-present-future.

a: difference between DM2 without PDN group versus DM2 with PDN group; b: difference between DM2 without PDN group versus control.
Regarding the postural balance (BESTest), the total score of the DM2 group with PDN presented worse performance and balance deficits $(p=0.025)$ when compared with subjects in the control group. In detailed domain analysis, on the biomechanical constraints section, the control group presented significantly better performance among the DM2 group without PDN ( $p=0.007)$ and with NPD ( $p=0.043$ ); no significant differences were found between the other domains (Table 3).

Table 3. Comparison of Balance Evaluation Systems in DM2 groups with and without PDN and control.

\begin{tabular}{c|c|c|c}
\hline & Control & Without PDN & With PDN \\
\cline { 2 - 4 } & $\begin{array}{c}\text { Mean (SD) } \\
\mathbf{n = 2 0}\end{array}$ & $\begin{array}{c}\text { Mean (SD) } \\
\mathbf{n = 2 0}\end{array}$ & $\begin{array}{c}\text { Mean (SD) } \\
\mathbf{n = 2 0}\end{array}$ \\
\hline BESTest total & $89.4(5.1)^{b}$ & $83.75(8.2)$ & $81.75(11.8)^{b}$ \\
\hline Biomechanical Constraints & $11.70(2.4)^{b . c}$ & $9.10(2.3)^{\mathrm{c}}$ & $9.65(2.9)^{\mathrm{b}}$ \\
\hline Stability Limits & $17.2(2.7)$ & $15.9(2.5)$ & $15.5(2.6)$ \\
\hline Anticipatory Postural Ajustments & $15.20(1.5)$ & $14.70(2.0)$ & $14.00(2.5)$ \\
\hline Reactive & $14.05(1.7)$ & $13.05(3.1)$ & $12.70(2.7)$ \\
\hline Sensory Orientation & $14.15(.9)$ & $14.00(1.5)$ & $13.60(2.4)$ \\
\hline Gait stability & $17.00(1.5)$ & $17.10(1.9)$ & $16.30(3.1)$ \\
\hline
\end{tabular}

ANOVA - Post hoc Bonferroni test. * $p \leq 0.05$

b: difference between control group versus DM2 with PDN; c: difference between control group versus DM2 without PDN.

Functional balance of the older adults was evaluated using the Neurocom Balance equipment; no significant difference was found between the groups in the sit-to-stand test. In the Step/Quick Turn, the older adults with DM2 and NPD had worse performance in the time spent on the left side $(p=0.030)$ compared with the control group, and in the Step up Over test, the control group performed the task faster than the DM2 group with PDN ( $p=0.004)$ (Table 4).

Table 4. Comparison of Functional Balance Evaluation (posturography) in groups DM2 with and without PDN and control.

\begin{tabular}{|c|c|c|c|}
\hline & Control & Without PDN & With PDN \\
\hline & $\begin{array}{c}\text { Mean (SD) } \\
\mathrm{n}=\mathbf{2 0}\end{array}$ & $\begin{array}{c}\text { Mean (SD) } \\
\mathrm{n}=\mathbf{2 0}\end{array}$ & $\begin{array}{c}\text { Mean (SD) } \\
n=20\end{array}$ \\
\hline \multicolumn{4}{|l|}{ Sit to Stand } \\
\hline Transfer time (sec) & $0.51(0.6)$ & $0.4(0.2)$ & $0.5(.03)$ \\
\hline Weight transfer (\%) & $19.5(8.9)$ & $17.0(5.1)$ & $20.1(10.1)$ \\
\hline Balance velocity ( $\%$ sec) & $9.4(15.5)$ & $4.15(1.1)$ & $4.15(1.0)$ \\
\hline \multicolumn{4}{|l|}{ Step/Quick Turn } \\
\hline Time spent in the task LS (sec) & $2.2(0.7)^{\mathrm{a}}$ & $2.3(0.7)$ & $3.1(1.5)^{\mathrm{a}}$ \\
\hline Time spent in the task RS (sec) & $2.3(0.7)$ & $2.41(0.7)$ & $2.91(1.3)$ \\
\hline Balance velocity - LS $\left({ }^{\circ} / \mathrm{s}\right)$ & $47.9(11.6)$ & $49.7(14.8)$ & $55.6(15.7)$ \\
\hline Balance velocity - RS $(\% / s)$ & $50.7(15.8)$ & $49.8(12.5)$ & $54.0(15.7)$ \\
\hline \multicolumn{4}{|l|}{ Step up and Over } \\
\hline Step up the step LS (\%) & $39.2(9.4)$ & $33.7(8.8)$ & $32.4(10.8)$ \\
\hline Step up the step RS (\%) & $39.7(8.5)$ & $37.7(9.0)$ & $33.1(12.1)$ \\
\hline Time spent in the task LS (sec) & $1.5(0.3)^{\mathrm{a}}$ & $1.8(0.5)$ & $1.9(0.5)^{\mathrm{a}}$ \\
\hline Time spent in the task RS (sec) & $1.5(0.3)$ & $1.7(.4)$ & $2.0(1.0)$ \\
\hline Impact to step down LS (\%) & $52.0(13.3)$ & $42.8(11.8)$ & $46.2(12.2)$ \\
\hline Impact to step down RS (\%) & $57.6(16.7)$ & $56.9(19.1)$ & $46.3(11.1)$ \\
\hline
\end{tabular}

ANOVA - Post hoc Bonferroni test. * $p \leq 0.05$

SD: standard deviation; sec: seconds; LS: left side; RS: right side; a: difference between control group versus DM2 with NPD; b: difeerence between DM2 without NPD group versus DM2 with NPD.

\section{DISCUSSION}

The main findings of this study were that PDN interfered negatively in QoL (sensory functioning domains, past, future and present 
activities; and death and dying), postural balance (total score and biomechanical constraints domain), functional balance (Step/Quick turn and Step up Over).

QoL in older adults was evaluated by the WHOQOL-OLD, which showed that the PDN compromised the sensorial abilities affecting daily life, thereby compromising their availability in participating in activities and interacting (sensory functioning domain). These findings corroborate that DM2 complications worsen the quality of health. ${ }^{16}$ In the domain of present, past and future activities, we have noticed that with time, DM2 and its complications, such as PDN, can cause dissatisfaction with life and culminate in anxieties about continuing to achieve or receive merit of life itself. Lee et al. ${ }^{17}$ associate several chronic diseases, especially DM2, with the worsening of QoL in this domain.

Our findings also confirmed that PDN interfered when older adults were analyzed in the death and dying domain. Neuropathy showed greater concern and fear of being unable to control death. Previous studies have shown that health status and chronic diseases such as DM2 can lead to greater vulnerability and dependence in old age, contributing to the reduction of well-being and QoL in older adults. 2,18 When the groups were submitted to the BESTest for postural balance analysis, in general, and in detailed dimension, we observed that the DM2 without and with PDN have losses in the body control in relation to the base of support. The disease can also be an aggravator of such clinical manifestations. Petrofsky et al. $.^{19} \mathrm{ob}-$ served that when they analyzed a group of older adults with DM2 and a control group, under full and low lighting conditions using computerized posturography, such group presented gait disturbances and higher risks of falls, previously to the sensory losses that could decrease the adaptation mechanism (lack of sensory feedback), because the altered balance leads to the redistribution of the feet pressure. ${ }^{19}$ With sensory losses in the feet, neuropathy tends not to complete the function of body balance in response to the disturbance, unable to achieve stability for a given task due to the deficiencies. ${ }^{20}$ The progressive nature of neuropathy can lead to loss of protective sensation in the feet, making them vulnerable to lesions and ulcerations. ${ }^{1}$

In detailed analysis (BESTest), in the biomechanical restrictions section, older adults of DM2 with and without PDN presented a destabilization regarding postural control, and this could start from the base of support, body alignment, amplitude and strength of the ankle-foot and hip, leading to postural imbalance. Stability limits affect movement selection and deficits in postural control and functional strength associated with PDN, interfere negatively in these parameters. ${ }^{21,22}$ As plantar innervation decreases, muscle wastage is observed. Over time, these imbalances lead to flexibility deformities that become progressively more rigid. ${ }^{1,23}$ Studies on different conditions (firm surface, foam surface, open and closed eyes in full, low and dark light, and in gait conditions) that prioritized the sensorial systems (visual and motor), show worse performance in patients with DM2, and the peripheral information caused by the disease, affect the postural balance and leave this population more susceptible to falls. ${ }^{19,24}$ Changes in the biomechanical properties can also be considered, since the calcaneus tendon is more rigid in these individuals, causing difficulties in maintaining the balance. ${ }^{25}$ In contrast, Fulk et al. ${ }^{26}$ concluded that despite changes detected, PDN may not be the only cause of impaired balance in people with the disease.

Neuropathy also showed impaired performance in functional balance tests. In the Quick walk and turn test, we observed that the PDN influenced the performance and execution of this task, evidencing the delay in the time spent to turn on the left side. The reaction time and walking speed of older adults with DM2 is slower and emphasize that changes in body positions may be useful in identifying a strategy for older adults with impaired balance. ${ }^{27}$

The time (seconds) to do the task Step up and Over involves: reaction time, motor activity and postural balance; PDN group needed more time to do this task, which may be related to decreased sensory inputs, an important source of information for the central nervous system (CNS) to perform and control the movement. There is a consensus among some authors ${ }^{7,25,26}$ that DM2, as well as PDN, leads to motor control disorders.

This study contributes to DM2 regarding functionality, showing possible guidelines of how to conduct an exercise program that can improve the physical abilities of these older adults, as well as prevent the risk of falls. Including a routine with postural balance and exercise will bring not only physical benefits to the older adults but will make their life safer (less risk of falls) and make them more confident and prepared to act more consciously and assertively. The limitations of this study are related to the multifactorial characteristics of both disease and motor control. As the focus of the research was motor control and quality of life, other aspects such as glycemic control and vision, which are also affected by DM2, were not analyzed.

\section{CONCLUSION}

This study showed that neuropaths presented worse physical performance and postural balance deficits, sensorial limitations, affecting daily tasks and, as a consequence, decreasing quality of life in Brazilian older adults.

\section{ACKNOWLEDGMENTS}

This study was funded in part by Coordenação de Aperfeiçoamento de Pessoal de Nível Superior - Brazil (Capes) - Finance Code 001.

AUTHORS' CONTRIBUTIONS: Each author contributed individually and significantly to the development of this article. RCE: substantial contribution to the design and writing of the study, final approval of the manuscript; GCB: critical revision of its intellectual content and final approval of the manuscript; NMSL: acquisition and final approval of the manuscript; AB: acquisition and final approval of the manuscript; DSG: acquisition and final approval of the manuscript DSB: writing and final approval of the manuscript; GSJ: writing and final approval of the manuscript; JMG: critical revision of its intellectual content and final approval of the manuscript; LEGL: critical revision of its intellectual content and final approval of the manuscript; ACA: statistical analysis; data interpretation and final approval of the manuscript.

\section{REFERENCES}

1. Boulton AJM, Armstrong DG, Albert SF, Frykberg RG, Hellman R, Kirkman MS, et al Comprehensive foot examination and risk assessment: a report of the task force of the foot care interest group of the American Diabetes Association, with endorsement by the American Association of Clinical Endocrinologists. Diabetes Care. 2008;31(8):1679-85

2. Riandini T, Wee HL, Khoo EYH, Tai BC, Wang W, Koh GCH, et al. Functional status mediates the association between peripheral neuropathy and health-related quality of life in individuals with diabetes. Acta Diabetol. 2018;55(2):155-64.

3. Lee PY, Tsai YJ, Liao YT, Yang YC, Lu FH, Lin SI. Reactive balance control in older adults with diabetes. Gait Posture. 2018;61:67-72.
4. Leonard DR, Farooqi MH, Myers S. Restoration of sensation, reduced pain, and improved balance in subjects with diabetic peripheral neuropathy: a double-blind, randomized, placebo-controlled study with monochromatic near-infrared treatment. Diabetes Care. 2004;27(1):168-72.

5. American Diabetes Association. 2. Classification and diagnosis of diabetes: standards of medical care in diabetes-2018. Diabetes Care. 2018;41 (Suppl 1):S13-27.

6. Sinclair A, Dunning T, Rodriguez-Mañas L. Diabetes in older people: new insights and remaining challenges. Lancet Diabetes Endocrinol. 2015;3(4):275-85. 
7. Toosizadeh N, Mohler J, Armstrong DG, Talal TK, Najafi B. The influence of diabetic peripheral neuropathy on local postural muscle and central sensory feedback balance control. PLoS One. 2015;10(8):0135255.

8. Chachamovich E, Fleck MP, Trentini C, Power M. Brazilian WHOQOL-OLD Module version: a Rasch analysis of a new instrument. Rev Saúde Pública. 2008;42(2):308-16.

9. Maia AC, Rodrigues-de-Paula F, Magalhães LC, Teixeira RLL. Cross-cultural adaptation and analysis of the psychometric properties of the balance evaluation systems test and MiniBESTest in the elderly and individuals with Parkinson's disease: Application of the Rasch model. Brazilian J Phys Ther. 2013;17(3):195-217.

10. Mendonça D, Alonso A, Greve J, Garcez-Leme L. Assessment of the quality of life, muscle strength, and dynamic balance of elderly Kendo players. Clinics. 2017;72(11):661-6.

11. Brech GC, Alonso AC, Luna NMS, Greve JM. Correlation of postural balance and knee muscle strength in the sit-to-stand test among women with and without postmenopausal osteoporosis. Osteoporos Int. 2013;24(7):2007-13.

12. Rahal MA, Alonso AC, Andrusaitis FR, Rodrigues TS, Speciali DS, Greve JMD, et al. Analysis of static and dynamic balance in healthy elderly practitioners of Tai Chi Chuan versus ballroom dancing. Clinics. 2015;70(3):157-61.

13. FLECK, MPA. O instrumento de avaliação de Qualidade de Vida da Organização Mundial de Saúde (WHOQOL-100): características e perspectivas. Revista Ciência e Saúde Coletiva, 2000;5(1):33-38.

14. FLECK MP, CHACHAMOVICH E, TRENTINI C. Development and validation of the Portuguese version of the WHOQOL-OLD modul. Ver. Saúde Pública 2006;40(5):785-91. Doi.org/10.1590/S0034-89102006000600007

15. Power M, Quinn K, Schimdt S. WHOQOL-OLD Group. Quality of Life Research. 2005;14:2197-2214. Doi: 10.1007/s1136-005-73809.

16. Graham JE, Stoebner-May DG, Ostir G V, Al Snih S, Peek MK, Markides K, et al. Health related quality of life in older Mexican Americans with diabetes: A cross-sectional study. Health Qual Life Outcomes. 2007 Jul;5(1):39.
17. Lee HC, Drake V, Cameron D. Identification of appropriate assessment criteria to measure older adults' driving performance in simulated driving. Aust Occup Ther J. 2002 Sep;49(3): 138-45.

18. Lee WJ, Song K-H, Noh JH, Choi YJ, Jo M-W. Health-related quality of life using the EuroQol 5D Questionnaire in Korean patients with type 2 diabetes. J Korean Med Sci. 2012;27(3):255-60.

19. Petrofsky JS, Cuneo M, Lee S, Johnson E, Lohman E. Correlation between gait and balance in people with and without type 2 diabetes in normal and subdued light. Med Sci Monit. 2006;12(7):CR273-81.

20. Jahn K, Zwergal A, Schniepp R. Gait disturbances in old age: classification, diagnosis, and treatment from a neurological perspective. Dtsch Arztebl Int. 2010;107(17):306-16.

21. Vaz MM, Costa GC, Reis JG, Junior WM, Albuquerque de Paula FJ, Abreu DC. Postural control and functional strength in patients with type 2 diabetes mellitus with and without peripheral neuropathy. Arch Phys Med Rehabil. 2013:94(12):2465-70.

22. Camargo MR, Barela JA, Nozabieli AJL, Mantovani AM, Martinelli AR, Fregonesi CEPT. Balance and ankle muscle strength predict spatiotemporal gait parameters in individuals with diabetic peripheral neuropathy. Diabetes Metab Syndr. 2015;9(2):79-84.

23. Boulton AJ. The diabetic foot: a global view. Diabetes Metab Res Rev. 2000;16 (Suppl 1):S2-5.

24. Huang X, Liu B, Sun J, Li X, Gong J, Duan J, et al. [Analysis and evaluation of the balance function in patients with type 2 diabetes]. Lin Chung Er Bi Yan Hou Tou Jing Wai Ke Za Zhi. 2016;30(1):27-30.

25. Cheing GLY, Chau RMW, Kwan RLC, Choi C-H, Zheng Y-P. Do the biomechanical properties of the ankle-foot complex influence postural control for people with type 2 diabetes? Clin Biomech (Bristol, Avon). 2013;28(1):88-92.

26. Fulk GD, Robinson CJ, Mondal S, Storey CM, Hollister AM. The effects of diabetes and/or peripheral neuropathy in detecting short postural perturbations in mature adults. J Neuroeng Rehabil. 2010;7(1):44.

27. Morrison S, Colberg SR, Parson HK, Vinik Al. Exercise improves gait, reaction time and postural stability in older adults with type 2 diabetes and neuropathy. J Diabetes Complications. 2014;28(5):715-22. 